Check for updates

Cite this: RSC Adv., 2017, 7, 35905

\title{
Syntheses, crystal structures and catalytic activities of two solvent-induced homotrinuclear Co(II) complexes with a naphthalenediol-based bis(Salamo)-type tetraoxime ligand $\uparrow$
}

\author{
Xiao-Yan Li, Le Chen, Lei Gao, Yang Zhang, Sunday Folaranmi Akogun \\ and Wen-Kui Dong (D)
}

Two homotrinuclear Co(॥) complexes, $\left[\mathrm{CO}_{3}(\mathrm{~L})(\mathrm{OAc})_{2}\left(\mathrm{CH}_{3} \mathrm{OH}\right)_{2}\right] 2 \mathrm{CHCl}_{3}$ (1) and $\left[\mathrm{CO}_{3}(\mathrm{~L})(\mathrm{OAc})_{2}\left(\mathrm{H}_{2} \mathrm{O}\right)_{2}\right]$ (2) based on a naphthalenediol-based acyclic bis(Salamo)-type tetraoxime ligand were synthesized. 1 and 2 were influenced by the coordinated methanol and water molecules, respectively, and their X-ray crystal structures revealed that they have similar molecular structures. Two terminal Co(॥) ions, located at the $\mathrm{N}_{2} \mathrm{O}_{2}$ coordination spheres of the Salamo moieties, are both in distorted trigonal-bipyramidal geometries, while the third $\mathrm{Co}(॥)$ ion in the central $\mathrm{O}_{4}$ cavity shows an octahedral geometry with two solvent molecules placed in the apical sites. Different solvent molecules lead to different supramolecular structures. The catecholase activities of 1 and 2 were examined using 3,5-di-tert-butylcatechol (3,5DTBC) in acetonitrile solution under completely aerobic conditions. The catalytic reaction follows Michaelis-Menten enzymatic reaction kinetics with turnover numbers $\left(K_{\text {cat }}\right)$ of $14.72 \mathrm{~h}^{-1}$ and $26.39 \mathrm{~h}^{-1}$

for 1 and 2, respectively.

Received 19th June 2017

Accepted 13th July 2017

DOI: 10.1039/c7ra06796h

rsc.li/rsc-advances

\section{Introduction}

The Salen-type ligand and its analogues continue to play significant roles in modern coordination chemistry. ${ }^{1}$ Their metal complexes have been explored to construct supramolecular structures ${ }^{2}$ and coordination polymers. ${ }^{1 e}$ Numerous investigations on these compounds, such as their luminescent properties, ${ }^{3}$ biological activities, ${ }^{4}$ catalysis activity, ${ }^{5}$ magnetic properties, ${ }^{6}$ electrochemical field ${ }^{7}$ and molecular recognition ${ }^{8}$ etc., also have been examined. Recently, many appropriate classes of Salen-type bisoxime compounds (Salamo and its derivatives) have been reported using $o$-alkyloxime units $(-\mathrm{CH}=$ $\left.\mathrm{N}-\mathrm{O}-\left(\mathrm{CH}_{2}\right)_{n}-\mathrm{O}-\mathrm{N}=\mathrm{CH}-\right)$ rather than the non $o$-alkyloxime $\left(-\mathrm{CH}=\mathrm{N}-\left(\mathrm{CH}_{2}\right)_{n}-\mathrm{N}=\mathrm{CH}-\right)$ units, and the large electronegativity of oxygen atoms is expected to strongly affect the electronic property of the $\mathrm{N}_{2} \mathrm{O}_{2}$ coordination sphere, which can lead to novel structures and different properties of the resulted complexes. Thus, Salamo-type ligands and their complexes have also been explored by Nabeshima group and ours, ${ }^{9}$ however, the bis(Salamo)-type metal complexes were rarely reported. ${ }^{10}$

Over the decades, Salen-type complexes ${ }^{11}$ have been widely utilized as catalysts in the industry, and functions in many

College of Chemical and Biological Engineering, Lanzhou Jiaotong University, Lanzhou, Gansu, 730070, P. R. China. E-mail: dongwk@126.com

$\dagger$ Electronic supplementary information (ESI) available. CCDC 1508735 and 1506120. For ESI and crystallographic data in CIF or other electronic format see DOI: $10.1039 / \mathrm{c} 7 \mathrm{ra06796h}$ important chemical reactions such as oxidation, reduction and polymerization..$^{12}$ However, studies on the participation of Salamo-type complexes in the catalytic process is yet to be explored. It has been known that the ubiquitous bio-enzyme catechol oxidase catalyzes exclusively the oxidation of catechols to the corresponding $o$-quinones in the presence of molecular oxygen. The active site of the catechol oxidase consists of a hydroxobridged dicopper(II) centre where each copper(II) centre is coordinated to three histidine nitrogens and adopts a trigonal pyramidal coordination geometry with one nitrogen in the apical site. ${ }^{13}$ Up to now, numerous researchers are designing new molecules that can give promising model complexes as effective replacements for catechol oxidase. The design of ligands has to satisfy a number of conditions such as metal-metal distance, steric effects, ${ }^{14}$ electronic and bridging ligand features, ${ }^{15}$ redox potentials,${ }^{16}$ and $\mathrm{pH}^{17}{ }^{17}$ Several model complexes have been reported to elucidate the structure-function relationship of this biocatalytic catechol-quinone conversion. Although most functional mimics of catechol oxidase are mono- and dinuclear $\mathrm{Cu}$ (II) complexes, other transition metal ions such as $\mathrm{Mn}(\mathrm{II} / \mathrm{III} / \mathrm{IV})$, and $\mathrm{Co}(\mathrm{III})$ can also serve as catalytically active complexes. ${ }^{18}$

And as far as we know, the current work is to first report the Salamo-type complex as a catechol oxidase model complex, which is a Salamo-type complex application provides a new idea.

As important raw materials and intermediates in organicchemical, catechins have a wide range of applications in 
agriculture, pharmaceutical, photographic materials and other fields. However, little research on Co(II) complexes has been done in regards to catecholase activity. Herein, we designed and synthesized a new acyclic naphthalenediol-based bis(Salamo)type tetraoxime ligand $\left(\mathrm{H}_{4} \mathrm{~L}\right)$ containing two Salamo moieties, which is likely to form multinuclear metal complexes. Two homotrinuclear $\mathrm{Co}$ (II) complexes (solv: $\mathrm{MeOH}$ and $\mathrm{H}_{2} \mathrm{O}$, respectively) were synthesized by the reaction of $\mathrm{H}_{4} \mathrm{~L}$ with $\mathrm{Co}$ (II) acetate tetrahydrate in different solvents. Due to the unique structure of Salamo-type complexes, a study shown that it is at least 104 times more stable than Salen-type complexes. ${ }^{19}$ It suggests that Salamo-type complexes have a unique advantage in catalysis. As far as we know, the present work is the first to report on the Salamo-type complexes as catechol oxidase model complexes, which provide a new idea for the application of Salamo-type complexes.

\section{Experimental}

\section{Materials and instruments}

All materials used were of high commercially available grade and were used as purchased. 3,5-Dibromosalicylaldehyde, methyl trioctyl ammonium chloride, pyridiniumchlorochromate and borontribromide were purchased from Alfa Aesar. Hydrobromic acid $33 \mathrm{wt} \%$ solution in acetic acid was purchased from J\&K Scientific Ltd and 3,5-di-tert-butylcatechol was bought from Tokyo Chemical Industry. The other reagents and solvents were from Tianjin Chemical Reagent Factory.

Elemental (carbon, hydrogen, and nitrogen) analyses were performed on GmbH VariuoEL V3.00 automatic elemental analyzer. Elemental analysis for Co was detected by an IRIS ER/ SWP-1 ICP atomic emission spectrometer. Melting points were measured by the use of a microscopic melting point apparatus made in Beijing Taike Instrument Limited Company. FT-IR spectra (400-4000 $\mathrm{cm}^{-1}$ ) were recorded on a VERTEX70 FT-IR spectrophotometer using $\mathrm{KBr}$ as medium. UV-vis absorption spectra were recorded on a Hitachi U-3900H spectrophotometer. ${ }^{1} \mathrm{H}$ NMR spectra were determined by German Bruker AVANCE DRX-400/600 spectroscopy.

\section{Synthesis of the ligand $\mathrm{H}_{4} \mathrm{~L}$}

1,2-Bis(aminooxy)ethane, $\quad 2$-[O-(1-ethyloxyamide)]oxime-4,6dibromophenol $^{\mathbf{1 9}}$ and 2,3-dihydroxynaphthalene-1,4-dicarbaldehyde ${ }^{20}$ were synthesized according to the analogous reported procedures. 2,3-Dihydroxynaphthalene-1,4-dicarbaldehyde $(0.354 \mathrm{~g}, 1.0 \mathrm{mmol})$ was added to the ethanol solution $(30 \mathrm{~mL})$ of 2-[O-(1-ethyloxyamide)]oxime-4,6-dibromophenol $(0.540 \mathrm{~g}$, $2.5 \mathrm{mmol}$ ). The suspension solution was stirred and refluxed at $45{ }^{\circ} \mathrm{C}$ for $4 \mathrm{~h}$ and then faint yellow solid of bis(Salamo)-type tetraoxime ligand $\left(\mathrm{H}_{4} \mathrm{~L}^{1}\right)$ was obtained, which was collected by suction filtration at $45{ }^{\circ} \mathrm{C}$ immediately, and washed with hot ethanol solution $\left(3 \times 10 \mathrm{~mL}, 45{ }^{\circ} \mathrm{C}\right)$ to give a yellow powder. Yield, $0.75 \mathrm{~g}$ (85\%). Mp 205-207 ${ }^{\circ} \mathrm{C}$. Anal. calc. for $\mathrm{C}_{30} \mathrm{H}_{24} \mathrm{Br}_{4} \mathrm{~N}_{4} \mathrm{O}_{8}$ : C, 40.57; H, 2.72; N, 6.31. Found: C, 40.54; $\mathrm{H}$, 2.74; N, 6.38\%. ${ }^{1} \mathrm{H}$ NMR (400 MHz, DMSO-d 6 , $\left.\delta, \mathrm{ppm}\right): 4.56$ (s, 8H, OCH-H), 7.38-7.40 (m, 2H, Ar-H), 7.69 (s, 2H, Ar-H), 7.81 (s,
2H, Ar-H), 8.47-8.49 (m, 2H, Ar-H), 8.51 (s, 2H, N=C-H), 9.10 (s, $2 \mathrm{H}, \mathrm{N}=\mathrm{C}-\mathrm{H}), 10.59$ (s, 4H, O-H). IR (KBr, cm $\left.{ }^{-1}\right): 3307$ (m), 3059 (m), 2927 (m), 2904 (m), 2854 (m), 1605 (m), 1433 (s), 1256 (m), $1212(\mathrm{~m})$. UV-vis $\left(\mathrm{CHCl}_{3} / \mathrm{CH}_{3} \mathrm{OH} 3: 2 \mathrm{v} / \mathrm{v}\right): \lambda_{\max }\left(\varepsilon_{\max }\right): 341,362$ and $380 \mathrm{~nm}\left(1.88 \times 10^{4}, 1.57 \times 10^{4}\right.$ and $\left.1.66 \times 10^{4} \mathrm{M}^{-1} \mathrm{~cm}^{-1}\right)$.

\section{Syntheses of the Co(II) complexes 1 and 2}

$\left[\mathrm{Co}_{3}(\mathrm{~L})(\mathbf{O A c})_{2}\left(\mathbf{C H}_{3} \mathrm{OH}\right)_{2}\right] \cdot \mathbf{2} \mathbf{C H C l}_{3}$ (1). A methanol solution (3 $\mathrm{mL})$ of $\mathrm{Co}(\mathrm{OAc})_{2} \cdot 4 \mathrm{H}_{2} \mathrm{O}(3.72 \mathrm{mg}, 0.015 \mathrm{mmol})$ was added to the suspended solution of $\mathrm{H}_{4} \mathrm{~L}(4.40 \mathrm{mg}, 0.005 \mathrm{mmol})$ in chloroform ( $2 \mathrm{~mL}$ ) and stirred for $2 \mathrm{~min}$. The solution turned to transparent and then filtered. Diffraction quality single crystals were obtained after few days on slow evaporation of the solution in open atmosphere. Brown blocks. Yield, $4.77 \mathrm{mg}$ (64\%). The experiments on larger scale also was performed under similar conditions. Anal. calc. for $\left[\mathrm{Co}_{3}(\mathrm{~L})(\mathrm{OAc})_{2}\left(\mathrm{CH}_{3} \mathrm{OH}\right)_{2}\right] 2 \mathrm{CHCl}_{3}$ $\left(\mathrm{C}_{38} \mathrm{H}_{36} \mathrm{~N}_{4} \mathrm{O}_{14} \mathrm{Br}_{4} \mathrm{Cl}_{6} \mathrm{Co}_{3}\right)$ : C, 30.80; H, 2.45; N, 3.78; Co, 11.93. Found: C, 30.85; H, 2.41; N, 3.73; Co, $11.90 \%$. IR ( $\left.\mathrm{KBr}, \mathrm{cm}^{-1}\right)$ : 3324 (m), 3066 (m), 2971 (m), 2896 (m), 1587 (m), 1440 (s), 1258 (m). UV-vis $\left(\mathrm{CHCl}_{3} / \mathrm{CH}_{3} \mathrm{OH} 3: 2 \mathrm{v} / \mathrm{v}\right): \lambda_{\max }\left(\varepsilon_{\max }\right) 371$ and $415 \mathrm{~nm}$ $\left(1.70 \times 10^{4}\right.$ and $\left.1.52 \times 10^{4} \mathrm{M}^{-1} \mathrm{~cm}^{-1}\right)$. UV-vis $(\mathrm{MeCN}): \lambda_{\max }$ $\left(\varepsilon_{\max }\right) 376$ and $416 \mathrm{~nm}\left(1.82 \times 10^{4}\right.$ and $\left.1.53 \times 10^{4} \mathrm{M}^{-1} \mathrm{~cm}^{-1}\right)$.

$\left[\mathrm{Co}_{3}(\mathbf{L})(\mathbf{O A c})_{2}\left(\mathbf{H}_{2} \mathbf{O}\right)_{2}\right](2)$. An i-PrOH$/ \mathrm{H}_{2} \mathrm{O}$ solution $(3: 0.5 \mathrm{v} / \mathrm{v}$, $3.5 \mathrm{~mL})$ of $\mathrm{Co}(\mathrm{OAc})_{2} \cdot 4 \mathrm{H}_{2} \mathrm{O}(5.20 \mathrm{mg}, 0.021 \mathrm{mmol})$ was added to the suspended solution of $\mathrm{H}_{4} \mathrm{~L}(6.16 \mathrm{mg}, 0.007 \mathrm{mmol})$ in $\left(\mathrm{CH}_{3}\right)_{2} \mathrm{CO} / \mathrm{CHCl}_{3}(2: 1 \mathrm{v} / \mathrm{v}, 3 \mathrm{~mL})$ and stirred for $20 \mathrm{~min}$. The solution turned to transparent and then filtered. Diffraction quality single crystals were obtained after few days on slow evaporation of the solution in open atmosphere. Brown needles. Yield, $4.61 \mathrm{mg}$ (54\%). The experiments on larger scale also was performed under similar conditions. Anal. calc. for $\left[\mathrm{Co}_{3}\right.$ $\left.(\mathrm{L})(\mathrm{OAc})_{2}\left(\mathrm{H}_{2} \mathrm{O}\right)_{2}\right]\left(\mathrm{C}_{34} \mathrm{H}_{30} \mathrm{Br}_{4} \mathrm{~N}_{4} \mathrm{O}_{14} \mathrm{Co}_{3}\right): \mathrm{C}, 33.61 ; \mathrm{H}, 2.49 ; \mathrm{N}$ 4.61; Co, 14.55. Found C, 33.67; H, 2.44; N, 4.57; Co, 14.49\%. IR ( KBr, $\mathrm{cm}^{-1}$ ): $3420(\mathrm{~m}), 3072(\mathrm{~m}), 2922(\mathrm{~m}), 2850(\mathrm{~m}), 1590(\mathrm{~m}), 1438$ (s), $1257(\mathrm{~m})$. UV-vis $\left(\mathrm{CHCl}_{3} / \mathrm{CH}_{3} \mathrm{OH} 3: 2 \mathrm{v} / \mathrm{v}\right): \lambda_{\max }\left(\varepsilon_{\max }\right) 371$ and $412 \mathrm{~nm}\left(1.55 \times 10^{4}\right.$ and $\left.1.32 \times 10^{4} \mathrm{M}^{-1} \mathrm{~cm}^{-1}\right)$. UV-vis $(\mathrm{MeCN}): \lambda_{\max }\left(\varepsilon_{\max }\right) 373$ and $413 \mathrm{~nm}\left(1.48 \times 10^{4}\right.$ and $1.29 \times$ $\left.10^{4} \mathrm{M}^{-1} \mathrm{~cm}^{-1}\right)$.

\section{Catalytic oxidation of 3,5-DTBC by 1 and 2 under complete aerobic condition}

$6.72 \mathrm{mg}(0.0045 \mathrm{mmol})$ of 1 and $1.00 \mathrm{~g}$ (4.54 mmol, 1000 equiv. of 1) of 3,5-DTBC were dissolved in $20 \mathrm{~mL}$ of MeCN. The solution was stirred for $48 \mathrm{~h}$ at room temperature and color was changed remarkably from light brown to deep red. The product was purified by column chromatography and recrystallized in diethyl ether to yield 3,5-DTBQ as red block-like crystals. 2 was also tested by the same methods.

\section{Crystal structure determination}

Intensity data for $\mathbf{1}$ and $\mathbf{2}$ were collected on a Bruker Smart 1000 CCD area detector with Mo-K$_{\alpha}$ radiation $(\lambda=0.71073 \AA)$. Reflection data were corrected for Lorentz and polarization factors and for absorption using the multi-scan method. The structures were solved by using the program SHELXL-2016 (ref. 21) and Fourier difference techniques, and refined by the full- 
matrix least-squares method based on $F^{2} \cdot{ }^{22}$ The hydrogen atoms (O13 and O14) of 1 were located in Fourier-difference maps and all the other hydrogen atoms were inserted in calculated positions with isotropic thermal parameters and refined. Nonhydrogen atoms were refined with anisotropic displacement parameters during the final cycles. All hydrogen atoms were placed in calculated positions with isotropic displacement parameters set to $1.2 \times U_{\text {eq }}$ of the attached atom. In addition, in complex 2 existence carbon atoms in the aromatic rings have high thermal motion (C25-C30) and disordered bromine atoms (Br3 and $\mathrm{Br} 4$ ), we use the command in the refinement process by ISOR restraint. The crystallographic data are summarized in Table 1. CCDC - 1508735 (1) and 1506120 (2).†

\section{Catecholase activity measurement}

UV-vis absorption spectra were measured on a Hitachi U-3900H spectrophotometer at $25{ }^{\circ} \mathrm{C}$. Solutions of 1 and $2\left(2.5 \times 10^{-5} \mathrm{M}\right)$ and 3,5-DTBC (in the range of $0.188 \mathrm{M}$ to $1.88 \mathrm{M}$ ) were prepared in MeCN (99.99\%). Different concentrations of 3,5-DTBC were added ( $2 \mu \mathrm{L}$ at a time) to $3 \mathrm{~mL}$ complex ( 1 or 2 ) solution to obtain mixed solution (final concentration of 3,5-DTBC ranges from $2.5 \times 10^{-3}$ to $\left.2.5 \times 10^{-2} \mathrm{M}\right)$. The absorption at $\lambda_{\max }=400 \mathrm{~nm}\left(\varepsilon=1900 \mathrm{M}^{-1}\right.$ $\mathrm{cm}^{-1}$ ), which is characteristic of the formed quinone, was measured as a function of time. A $2.5 \times 10^{-5} \mathrm{M}$ solution of 1 with 100 equiv. of 3,5-DTBC was used and the solution saturated under

Table 1 X-ray crystallographic data for 1 and 2

\begin{tabular}{|c|c|c|}
\hline Complex & 1 & 2 \\
\hline Formula & $\mathrm{C}_{38} \mathrm{H}_{36} \mathrm{~N}_{4} \mathrm{O}_{14} \mathrm{Br}_{4} \mathrm{Cl}_{6} \mathrm{Co}_{3}$ & $\mathrm{C}_{34} \mathrm{H}_{30} \mathrm{Br}_{4} \mathrm{~N}_{4} \mathrm{O}_{14} \mathrm{Co}_{3}$ \\
\hline Formula weight & 1481.84 & 1215.05 \\
\hline Wavelength $(\AA)$ & 0.71073 & 0.71073 \\
\hline Crystal system & Triclinic & Monoclinic \\
\hline Space group & $P \overline{1}$ & $P 2_{1} / c$ \\
\hline$a(\AA)$ & $14.5421(10)$ & $19.182(2)$ \\
\hline$b(\stackrel{\circ}{\AA})$ & $14.8347(13)$ & $18.751(2)$ \\
\hline$c(\AA)$ & $17.3221(18)$ & $18.722(2)$ \\
\hline$\alpha(\mathrm{deg})$ & $113.715(9)$ & 90.00 \\
\hline$\beta$ (deg) & $90.013(7)$ & $113.6144(18)$ \\
\hline$\gamma(\mathrm{deg})$ & $108.037(7)$ & 90.00 \\
\hline$V\left(\AA^{3}\right)$ & $3137.4(2)$ & $6169.9(12)$ \\
\hline$Z, D_{\text {calc }}\left(\mathrm{g} \mathrm{cm}^{-3}\right)$ & $2,1.529$ & $4,1.308$ \\
\hline$\theta$ range (deg) & $3.529-26.022$ & $1.588-25.499$ \\
\hline$F(000)$ & 1454 & 2380 \\
\hline Crystal size (mm) & $0.21 \times 0.22 \times 0.31$ & $\begin{array}{l}0.22 \times 0.25 \\
\times 0.28\end{array}$ \\
\hline Index ranges & $\begin{array}{l}-17 \leq h \leq 17 \\
-17 \leq k \leq 18 \\
-19 \leq l \leq 21\end{array}$ & $\begin{array}{l}-16 \leq h \leq 23 \\
-22 \leq k \leq 20 \\
-22 \leq l \leq 22\end{array}$ \\
\hline Reflections & $21805 / 12621$ & $35080 / 11495$ \\
\hline collected/unique & {$\left[R_{\mathrm{int}}=0.0601\right]$} & {$\left[R_{\mathrm{int}}=0.0527\right]$} \\
\hline $\begin{array}{l}\text { Completeness } \\
(\%)(\theta)\end{array}$ & $99.5(26.022)$ & $99.9(26.022)$ \\
\hline $\begin{array}{l}\text { Data/restraints/ } \\
\text { parameters }\end{array}$ & $12621 / 6 / 632$ & $11491 / 12 / 610$ \\
\hline Goodness-of-fit on $F^{2}$ & 0.913 & 1.077 \\
\hline$R_{1}^{a} / \mathrm{W} R_{2}^{b}[I>2 \sigma(I)]$ & $0.0721 / 0.1693$ & $0.0568 / 0.1519$ \\
\hline
\end{tabular}

complete aerobic condition. Under these conditions, catechol was hardly oxidized in the absence of complexes. The kinetic parameters were determined for $2.5 \times 10^{-5} \mathrm{M}$ solutions of 1 and 2 and $2.5 \times 10^{-3}$ to $2.5 \times 10^{-2} \mathrm{M}$ solutions of the substrate.

\section{Results and discussion}

\section{Formations and characterizations of $\mathrm{H}_{4} \mathrm{~L}$ and its $\mathrm{Co}$ (II) complexes}

The reaction of 2,3-dihydroxynaphthalene-1,4-dicarbaldehyde with 2-[O-(1-ethyloxyamide)]oxime-4,6-dibromophenol in ethanol gave the acyclic bis(Salamo)-type tetraoxime ligand $\left(\mathrm{H}_{4} \mathrm{~L}\right)$, which was collected by suction filtration. When $\mathrm{H}_{4} \mathrm{~L}$ combines with two equivalents of $\mathrm{Co}(\mathrm{II})$ ions, the acyclic structural form may be change into a C-shaped form to give a central cavity (Scheme 1a). The intermediate complex is expected to have a high affinity toward another metal ion, since the donor atoms are arranged in a cyclic fashion and negatively charged, which tends to form trinuclear metal complexes and have been proven by UV-vis titration experiment.

In the $\mathrm{UV}$-vis titration experiment of $\mathbf{1}$, the color of a solution of $\mathrm{H}_{4} \mathrm{~L}$ in $\mathrm{CHCl}_{3} / \mathrm{MeOH}(3: 2 \mathrm{v} / \mathrm{v}$, at this condition, the single crystals of 1 were obtained) gradually changed from colorless to light brown upon addition of a solution of $\mathrm{Co}$ (II) acetate. For $\mathrm{H}_{4} \mathrm{~L}$, the peaks at 342,361 and $380 \mathrm{~nm}$ can be assigned to the intra-ligand $\pi-\pi *$ transitions. Upon addition of Co(II) ion, these peaks gradually disappeared with the emergence of new peaks at 369 and $414 \mathrm{~nm}$. The former absorption peak at $369 \mathrm{~nm}$ can be attributed to $\pi-\pi^{*}$ transitions, ${ }^{9 d}$ while the latter one at near $414 \mathrm{~nm}$ in the low energy region may be due to $\mathrm{L} \rightarrow$ M chargetransfer transition, which are characteristic of the transition metal complexes with $\mathrm{N}_{2} \mathrm{O}_{2}$ coordination spheres. ${ }^{23}$ However, the absorbance of the solution hardly changed after $\mathrm{Co}(\mathrm{II})$ ion was added up to 3 equiv. (Fig. 1). Spectroscopic titration clearly indicates the reaction stoichiometry ratio of $1: 3$ as shown in the homotrinuclear $\mathrm{Co}(\mathrm{II})$ complex, although the ligand $\mathrm{H}_{4} \mathrm{~L}$ only has two Salamo chelate moieties.

In order to obtain different $\mathrm{Co}(\mathrm{II})$ complexes influenced by the coordinated solvents, various solvents were used as reaction mediums. 1 and $\mathbf{2}$ were obtained by the addition of different solutions of $\mathrm{Co}$ (II) acetate to a suspended solution of $\mathrm{H}_{4} \mathrm{~L}$ at room temperature, and the solutions changed from turbid to transparent. Slow evaporation of the solutions in open atmosphere resulted in the formation of brown polyhedral crystals of 1 and 2 (solv: $\mathrm{MeOH}$ and $\mathrm{H}_{2} \mathrm{O}$, respectively). It is worth noting that the reaction of $\mathrm{Co}$ (II) acetate with $\mathrm{H}_{4} \mathrm{~L}$ in the presence of methanol in the $3: 1$ molar ratio, respectively, resulted in the coordination of methanol molecules, however, when $\mathrm{Co}$ (II) acetate and $\mathrm{H}_{4} \mathrm{~L}$ reacted in the presence of $\mathrm{i}-\mathrm{PrOH} / \mathrm{H}_{2} \mathrm{O}(3: 0.5 \mathrm{v} /$ v), it was water molecules that coordinated to the central $\mathrm{Co}$ (II) rather than isopropanol molecules (Scheme 1b).

The binding modes were determined by comparing FT-IR spectra of the ligand $\mathrm{H}_{4} \mathrm{~L}$ with those of its complexes (Fig. 2). The free ligand $\mathrm{H}_{4} \mathrm{~L}$ exhibits characteristic $\mathrm{C}=\mathrm{N}$ and $\mathrm{Ar}-\mathrm{O}$ stretching bands at ca. 1605 and $1244 \mathrm{~cm}^{-1}$, respectively. Upon complexation, the $\mathrm{C}=\mathrm{N}$ and $\mathrm{Ar}-\mathrm{O}$ bonds shift to the lower frequencies and are therefore a proof of the coordination of 


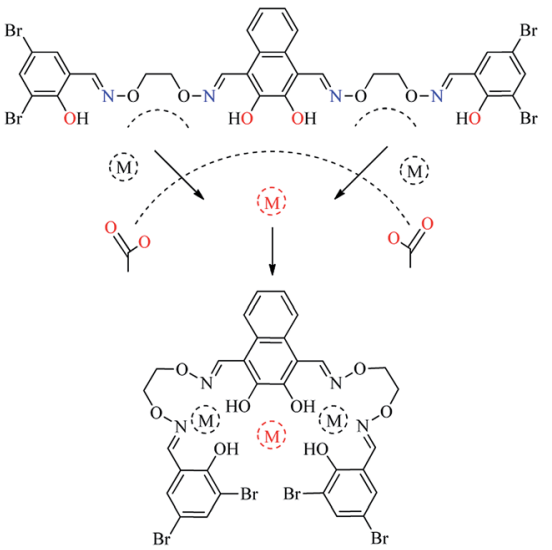

(a)
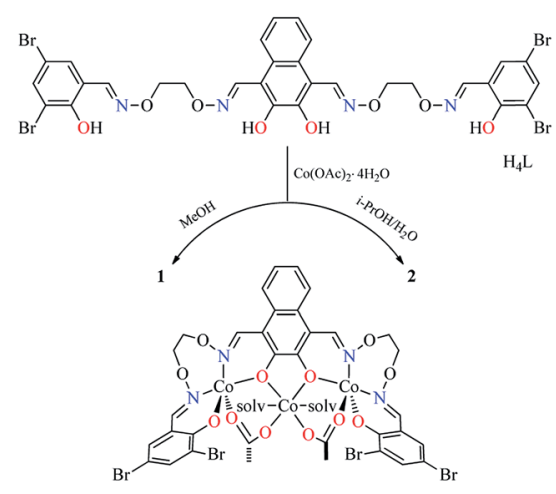

solv $=\mathrm{MeOH}(\mathbf{1})$ or $\mathrm{H}_{2} \mathrm{O}(\mathbf{2})$

(b)

Scheme 1 Possible coordination pattern (a) and formations of 1 and 2 (b).

azomethine nitrogen and phenolic oxygen to $\mathrm{Co}(\mathrm{II}) .{ }^{24}$ The free ligand $\mathrm{H}_{4} \mathrm{~L}$ shows the expected absorption band at $c a .3420$ $\mathrm{cm}^{-1}$, evidence for the vibration of phenolic OH groups. The expected absorption bands in $\mathbf{1}$ and $\mathbf{2}$ are observed at $c a .3324$ and $3420 \mathrm{~cm}^{-1}$, indicating the presence of coordinated methanol and water molecules, respectively. In addition, the bending and wagging modes of coordinated water molecules appears at ca. 1638 and $530 \mathrm{~cm}^{-1}$ in 2, which is not found in $\mathrm{H}_{4} \mathrm{~L}$ and $\mathbf{1}$. This phenomenon indicates that water molecules are involved in the coordination of $2 . .^{25}$

\section{Description of crystal structures}

The asymmetric unit of the homotrinuclear $\mathbf{1}$ is shown in Fig. 3, and their bond lengths and bond angles are listed in Table 2 .

The single-crystal X-ray structures revealed the differences between methanol and water solvates are relatively minor, which also very similar to the analogous homotrinuclear $\mathrm{Co}(\mathrm{II})$

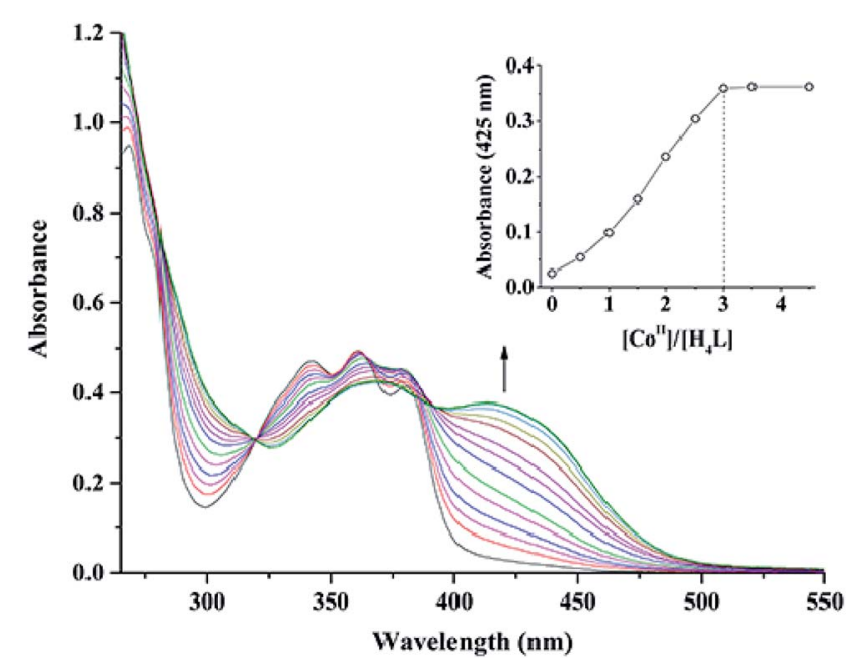

Fig. 1 UV-vis spectral changes of $\mathrm{H}_{4} \mathrm{~L}$ by the addition of $\mathrm{Co}(\mathrm{OAc})_{2}$ $\left(\mathrm{CHCl}_{3} / \mathrm{CH}_{3} \mathrm{OH} 3: 2 \mathrm{v} / \mathrm{v},\left[\mathrm{H}_{4} \mathrm{~L}\right]=2.5 \times 10^{-5} \mathrm{M}\right)$. The inset shows the plot of absorbance at $425 \mathrm{~nm}$ versus the molar ratio $\left[\mathrm{Co}^{\| \prime}\right] /\left[\mathrm{H}_{4} \mathrm{~L}\right]$. complex coordinated by ethanol in the central position, designed and reported by Nabeshima group. ${ }^{10}$ Two terminal Co(II) ions (Co1 and Co3) are located at the $\mathrm{N}_{2} \mathrm{O}_{2}$ coordination spheres of Salamo moieties, while the third one (Co2) is located in the $\mathrm{O}_{2}$ sites (O4 and $\left.\mathrm{O} 5\right) \cdot{ }^{10} \mathrm{Co} 2$ is bridged by $\mathrm{Co} 1$ and $\mathrm{Co} 3$ through two deprotonated phenoxo donors $\mathrm{O} 4$ and $\mathrm{O} 5$, respectively, as well as two acetate ions in a $\mu_{2}-\eta^{1}: \eta^{1}$ fashion. The bond distances between Co1 and Co2 (complex 1: 3.545(2) $\AA$ and complex 2: 3.530(1) $\AA$ ) are longer than that between Co2 and Co3 (complex 1: 3.530(1) $\AA$ and complex 2: 3.470(1) $\AA$ ). Interestingly, $\mathrm{Co} 1$ and $\mathrm{Co} 3$ in both complexes are pentacoordinated and so, would be expected to experience the same coordination environment. Resulting geometries of Co1 and Co3 are both distorted trigonal-bipyramidal geometries (complex 1: $\tau / \chi=0.838 / 0.927$ (Co1), 0.765/0.840 (Co3) and complex 2: $\tau / \chi=0.882 / 0.900$ (Co1), 0.750/0.877 (Co3)), ${ }^{26}$ whose axial positions are occupied by the N1-O4 and N4-O5 donors, respectively. The central $\mathrm{Co} 2$ has an octahedral geometry with six oxygen-donor atoms including two $\mu_{2}$-acetato ligands and

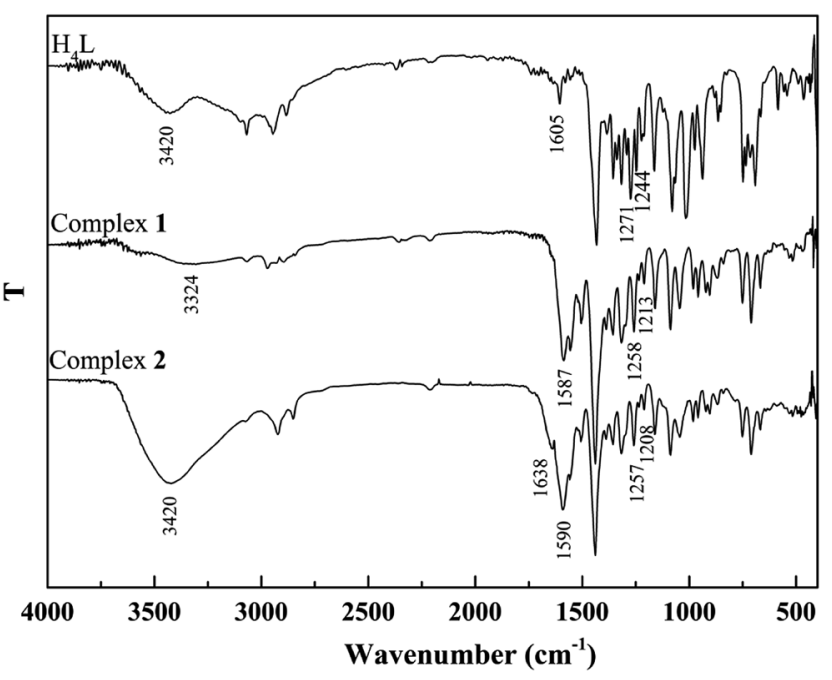

Fig. 2 FT-IR spectra of the ligand and its corresponding complexes. 


.
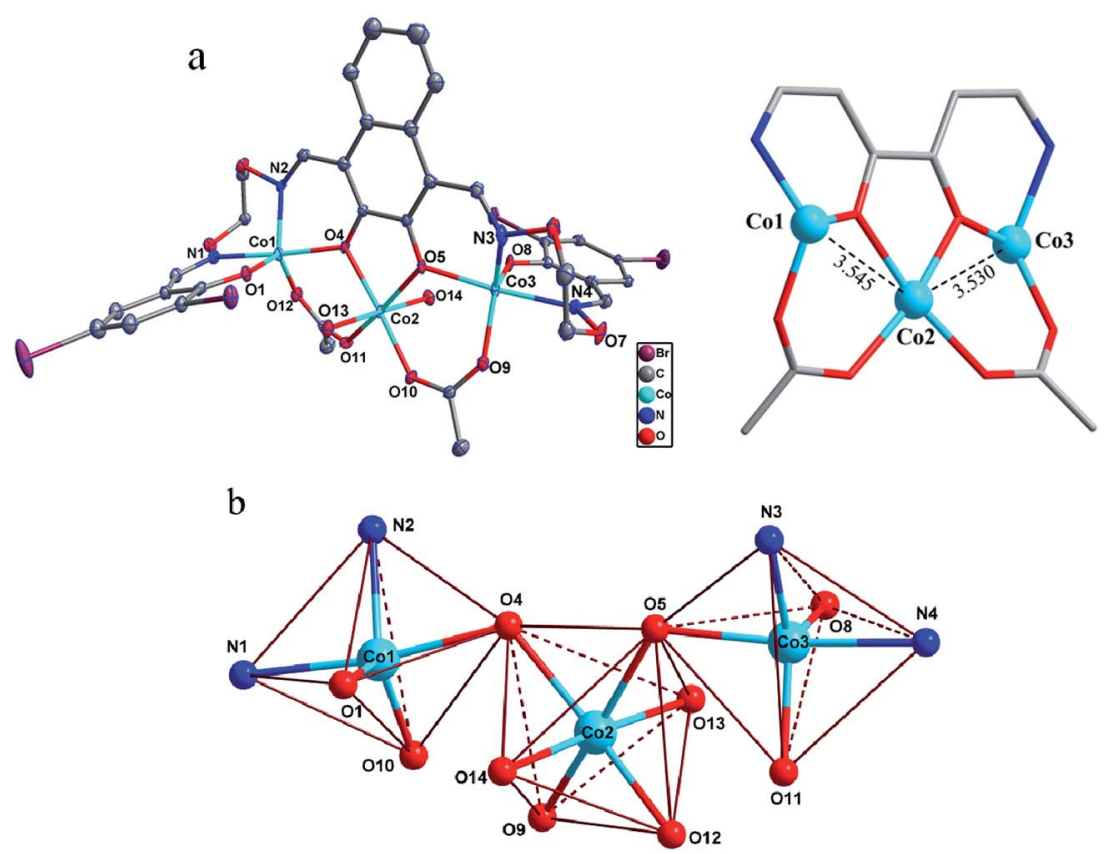

Fig. 3 (a) Molecule structure and atom numberings of 1 (thermal ellipsoids at 30\% probability, hydrogen atoms and the solvated chloroform molecules have been omitted for clarity). (b) The coordination polyhedrons and the spatial relationship of Co(॥) centres.

two solvent molecules. Oxygen-donor atoms of $(\mathrm{L})^{4-}$ and $\mu_{2^{-}}$ acetato ligands form the equatorial plane and the oxygen-donor atoms of the solvent molecules are placed in the apical sites. Owing to these coordination geometries, four 6-membered rings and one central 5-membered ring are constructed, which are connected through the Co(II) centers and display a polycyclic geometry (Fig. 3a). The coordination polyhedrons and the spatial relationship of Co(II) centers are shown in Fig. 3b. A comparison between the isostructural complexes 1 and 2 (Fig. 4) shows that the $\mathrm{CoN}_{2} \mathrm{O}_{2}$ fragments of $\mathbf{1}$ are more distorted than

Table 2 Selected bond distances $(\AA \AA)$ and angles $\left({ }^{\circ}\right)$ for 1 and 2

\begin{tabular}{|c|c|c|c|c|c|}
\hline & 1 & 2 & & 1 & 2 \\
\hline Co1-O1 & $1.938(6)$ & $1.942(3)$ & $\mathrm{Co} 2-\mathrm{O} 4$ & $2.097(5)$ & 2.101(3) \\
\hline Co1-O4 & $2.083(5)$ & $2.056(3)$ & $\mathrm{Co} 2-\mathrm{O} 5$ & $2.084(5)$ & $2.063(3)$ \\
\hline Co1-O10 & $1.956(5)$ & $1.971(4)$ & $\mathrm{Co} 2-\mathrm{O} 9$ & $2.067(5)$ & $2.092(3)$ \\
\hline Co1-N1 & $2.120(6)$ & $2.134(4)$ & $\mathrm{Co} 2-\mathrm{O} 12$ & $2.049(6)$ & $2.051(4)$ \\
\hline Co1-N2 & $2.039(7)$ & $2.020(4)$ & $\mathrm{Co} 2-\mathrm{O} 13$ & $2.132(6)$ & $2.068(3)$ \\
\hline Co3-O5 & $2.071(5)$ & $2.066(3)$ & Co2-O14 & $2.117(6)$ & $2.125(3)$ \\
\hline Co3-O8 & $1.938(6)$ & $1.935(3)$ & Co3-N3 & $2.041(5)$ & $2.025(5)$ \\
\hline Co3-O11 & $1.975(6)$ & 1.994(4) & Co3-N4 & $2.129(7)$ & $2.132(4)$ \\
\hline O1-Co1-O4 & $95.1(2)$ & $96.40(13)$ & $\mathrm{O} 4-\mathrm{Co} 2-\mathrm{O} 5$ & $77.60(18)$ & 77.61(13) \\
\hline O1-Co1-O10 & 121.3(3) & $124.59(16)$ & $\mathrm{O} 4-\mathrm{Co} 2-\mathrm{O} 9$ & $96.6(2)$ & 95.91(13) \\
\hline O1-Co1-N1 & $87.6(3)$ & $86.63(14)$ & $\mathrm{O} 4-\mathrm{Co} 2-\mathrm{O} 12$ & $168.7(2)$ & $171.33(14)$ \\
\hline $\mathrm{O} 1-\mathrm{Co} 1-\mathrm{N} 2$ & $117.0(3)$ & $111.82(16)$ & $\mathrm{O} 4-\mathrm{Co} 2-\mathrm{O} 13$ & $97.3(2)$ & $96.52(13)$ \\
\hline $\mathrm{O} 4-\mathrm{Co} 1-\mathrm{O} 10$ & $94.0(2)$ & $94.90(14)$ & $\mathrm{O} 4-\mathrm{Co} 2-\mathrm{O} 14$ & $85.0(2)$ & $85.04(13)$ \\
\hline O4-Co1-N1 & $172.0(2)$ & 175.95(15) & O5-Co2-O9 & $167.2(2)$ & $166.97(13)$ \\
\hline $\mathrm{O} 4-\mathrm{Co} 1-\mathrm{N} 2$ & $82.9(2)$ & $84.31(14)$ & $\mathrm{O} 5-\mathrm{Co} 2-\mathrm{O} 12$ & $97.75(19)$ & $99.61(14)$ \\
\hline O10-Co1-N1 & $91.1(2)$ & $85.55(15)$ & $\mathrm{O} 5-\mathrm{Co} 2-\mathrm{O} 13$ & $83.51(19)$ & 85.91(13) \\
\hline O10-Co1-N2 & $121.7(3)$ & $123.22(15)$ & $\mathrm{O} 5-\mathrm{Co} 2-\mathrm{O} 14$ & $98.0(2)$ & $94.55(13)$ \\
\hline N1-Co1-N2 & $89.1(3)$ & $92.07(16)$ & O5-Co3-N3 & $84.5(2)$ & $83.62(15)$ \\
\hline O5-Co3-O8 & $93.9(2)$ & $94.39(13)$ & O5-Co3-N4 & $173.2(2)$ & $173.99(16)$ \\
\hline O5-Co3-O11 & $95.5(2)$ & $97.85(14)$ & $\mathrm{O} 9-\mathrm{Co} 2-\mathrm{O} 12$ & $90.0(2)$ & $88.37(14)$ \\
\hline O8-Co3-O11 & $118.6(2)$ & $118.57(16)$ & $\mathrm{O} 9-\mathrm{Co} 2-\mathrm{O} 13$ & $86.0(2)$ & $83.60(13)$ \\
\hline O8-Co3-N3 & $114.0(2)$ & $112.52(17)$ & O9-Co2-O14 & $92.8(2)$ & $96.14(14)$ \\
\hline O8-Co3-N4 & $87.5(3)$ & $87.06(14)$ & $\mathrm{O} 12-\mathrm{Co} 2-\mathrm{O} 13$ & $92.4(2)$ & 91.44(14) \\
\hline O11-Co3-N3 & $127.3(2)$ & $128.55(17)$ & $\mathrm{O} 12-\mathrm{Co} 2-\mathrm{O} 14$ & $85.5(2)$ & $87.02(14)$ \\
\hline O11-Co3-N4 & $89.7(3)$ & $86.54(15)$ & $\mathrm{O} 13-\mathrm{Co} 2-\mathrm{O} 14$ & $177.6(2)$ & $178.44(15)$ \\
\hline N3-Co3-N4 & $88.8(2)$ & $90.44(16)$ & & & \\
\hline
\end{tabular}




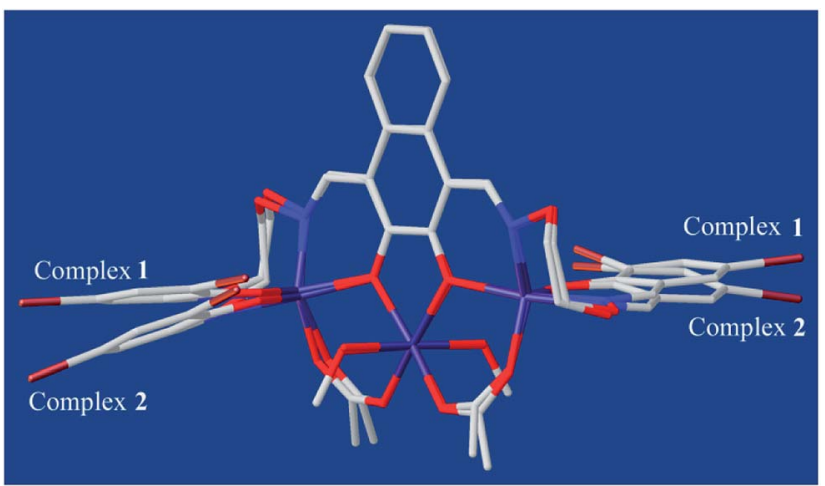

Fig. 4 Comparison of the molecular structures of 1 and 2 by overlay map (naphthalene rings as the basal planes).

those of 2. Terminal salicylidene moieties of $\mathbf{1}$ and $\mathbf{2}$ are dangling in the opposite side, and the dihedral angles between the basal planes (naphthalene ring) and the phenyl rings are shown in Table 2. Compared with 2 , the terminal salicylidene moieties of $\mathbf{1}$ are more deviated from the basal planes, which is likely to be caused by steric hindrance effect of coordinated solvent molecules.

The corresponding interactions of $\mathbf{1}$ and $\mathbf{2}$ are summarized in Table 3, where the coordinated solvent molecules play important roles in the construction of supramolecular structures owing to the formation of abundant intra- and intermolecular hydrogen bonds. For 1, hydrogen atoms from two coordinated methanol molecules (-O14H14, -C35H35C,
-O13H13 and -C36H36B) form hydrogen bonds with phenoxo (O1 and $\mathrm{O} 8$ ), bromine (Br1 and $\mathrm{Br} 4$ ) atoms and oxygen atoms of acetate ions (O12 and O9). Oxygen atoms (O10 and O11) of acetate ions act as acceptor to form two hydrogen bonds with the protons $(-\mathrm{C} 8 \mathrm{H} 8 \mathrm{~B}$ and $-\mathrm{C} 23 \mathrm{H} 23 \mathrm{~B})$ of ethylenedioxime carbons in each molecule (Fig. 5a). In addition, complex molecules form a dimer structure by a pair of intermolecular

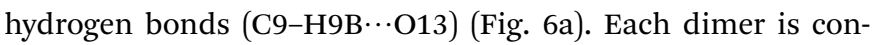
nected to two uncoordinated chloroform molecules and each chloroform molecule is connected to two dimers via intermo-

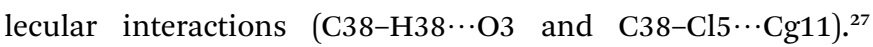
Interestingly, a series of circular units are constructed by the above-mentioned intermolecular interactions, forming a 1D supramolecular chain (Fig. 6b). For 2, one of the two coordinated water hydrogen atoms $(-\mathrm{O} 14 \mathrm{H} 14 \mathrm{~A}$ and $-\mathrm{O} 14 \mathrm{H} 14 \mathrm{~B})$ forms hydrogen bonds with phenoxo and bromine atoms (O1 and $\mathrm{Br} 1)$, whereas another water hydrogen atom $(-\mathrm{O} 13 \mathrm{H} 13 \mathrm{~A})$ just forms one hydrogen bond with phenoxo atom (O8) probably because of the long distances (H13A $\cdots \mathrm{Br} 4,2.960 \AA$ and $\mathrm{H} 13 \mathrm{~B} \cdots$ $\mathrm{Br} 4,3.809 \AA$ ). In addition, acetate ions (O10 and O11) act as acceptor to form two hydrogen bonds with the protons $(-\mathrm{C} 8 \mathrm{H} 8 \mathrm{~B}$ and $-\mathrm{C} 23 \mathrm{H} 23 \mathrm{~B}$ ) of ethylenedioxime carbons in each molecule (Fig. 5b). Furthermore, two adjacent molecules are interlinked by three intermolecular hydrogen bonds (C9-H9B $\cdots \mathrm{O} 14, \mathrm{C} 22-$ $\mathrm{H} 22 \mathrm{~A} \cdots \mathrm{O} 10$ and $\mathrm{C} 22-\mathrm{H} 22 \mathrm{~B} \cdots \mathrm{O} 13)$ to form a $1 \mathrm{D}$ chain supramolecular structure, and adjacent chains are further connected to each other via the $\pi \cdots \pi$ stacking interactions ( $\mathrm{Cg} 10 \cdots \mathrm{Cg} 10)$, resulting in a $2 \mathrm{D}$ supramolecular structure (Fig. 7). ${ }^{28}$

Table 3 Hydrogen bond, $\mathrm{C}-\mathrm{H} \cdots \pi, \mathrm{C}-\mathrm{Cl} \cdots \pi$ and $\pi \cdots \pi$ stacking interactions in 1 and $2\left(\AA,{ }^{\circ}\right)$

\begin{tabular}{|c|c|c|c|c|c|c|}
\hline $\mathrm{D}-\mathrm{X}$ & $d(\mathrm{D}-\mathrm{X})$ & $d(\mathrm{X} \cdots \mathrm{A})$ & $d(\mathrm{D} \cdots \mathrm{A})$ & $\angle \mathrm{D}-\mathrm{X} \cdots \mathrm{A}$ & A & Symmetry codes \\
\hline \multicolumn{7}{|l|}{ Complex 1} \\
\hline O13-H13 & 0.86 & 2.67 & $3.465(12)$ & 155 & $\mathrm{Br} 4$ & \multirow{9}{*}{$\begin{array}{l}{[1-x, 2-y,-z]} \\
{[1+x, y, z]} \\
{[1-x, 2-y, 1-z]} \\
{[x, y, z]}\end{array}$} \\
\hline O14-H14 & 0.86 & 2.6 & $3.387(13)$ & 154 & Br1 & \\
\hline O14-H14 & 0.86 & 2.27 & $2.762(17)$ & 116 & O1 & \\
\hline C8-H8B & 0.97 & 2.29 & $3.14(2)$ & 146 & O10 & \\
\hline C36-H36B & 0.96 & 2.59 & $3.17(3)$ & 120 & O9 & \\
\hline C9-H9B & 0.97 & 2.52 & $3.408(10)$ & 153 & O13 & \\
\hline C38-H38 & 0.98 & 2.59 & $3.183(16)$ & 119 & O3 & \\
\hline C37-H37 & 0.98 & 2.57 & $3.440(16)$ & 148 & $\operatorname{Cg} 10^{a}$ & \\
\hline $\mathrm{C} 38-\mathrm{Cl} 5$ & $1.68(2)$ & $3.475(7)$ & $4.889(16)$ & $140.6(6)$ & $\operatorname{Cg} 11^{b}$ & \\
\hline C8-H8B & 0.97 & 2.36 & $3.153(7)$ & 139 & O10 & \multirow{6}{*}{$\begin{array}{l}{[x, 3 / 2-y, 1 / 2+z]} \\
{[x, 3 / 2-y,-1 / 2+z]} \\
{[x, 3 / 2-y,-1 / 2+z]} \\
{[1-x, 1-y,-z]}\end{array}$} \\
\hline $\mathrm{O} 23-\mathrm{H} 23 \mathrm{~B}$ & 0.97 & 2.38 & $3.191(7)$ & 141 & O11 & \\
\hline C9-H9B & 0.97 & 2.54 & $3.188(6)$ & 124 & O14 & \\
\hline $\mathrm{C} 22-\mathrm{H} 22 \mathrm{~A}$ & 0.97 & 2.52 & $3.448(7)$ & 160 & O10 & \\
\hline $\mathrm{C} 22-\mathrm{H} 22 \mathrm{~B}$ & 0.97 & 2.44 & $3.285(7)$ & 147 & O13 & \\
\hline $\operatorname{Cg} 10^{c}$ & & & $3.686(4)$ & & $\operatorname{Cg} 10^{c}$ & \\
\hline
\end{tabular}

${ }^{a} \mathrm{Cg} 10=\mathrm{C} 15-\mathrm{C} 20 .{ }^{b} \mathrm{Cg} 11=\mathrm{C} 25-\mathrm{C} 30 .{ }^{c} \mathrm{Cg} 10=\mathrm{C} 15-\mathrm{C} 20$. 
$\mathrm{a}$



b

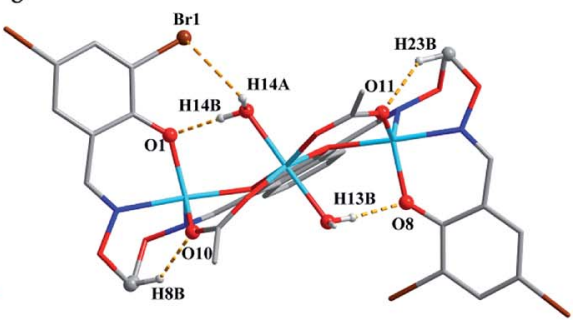

Fig. 5 View of the abundant intramolecular hydrogen bonds of 1 (a) and 2 (b).

\section{Catecholase activity: spectrophotometric study}

Though analogous bis(Salamo)-type Co(II) complex has been also synthesized by Nabeshima group, the study on catalytic activity of Salamo-type compounds has not been reported up to now. ${ }^{10}$ In order to initiate a new field for the Salamo-type compounds, we studied the catecholase activities of the two Co(II) complexes and utilized the most commonly used substrate, 3,5-di-tert-butylcatechol (3,5-DTBC) due to its low reduction potential for the quinone-catechol couple, which

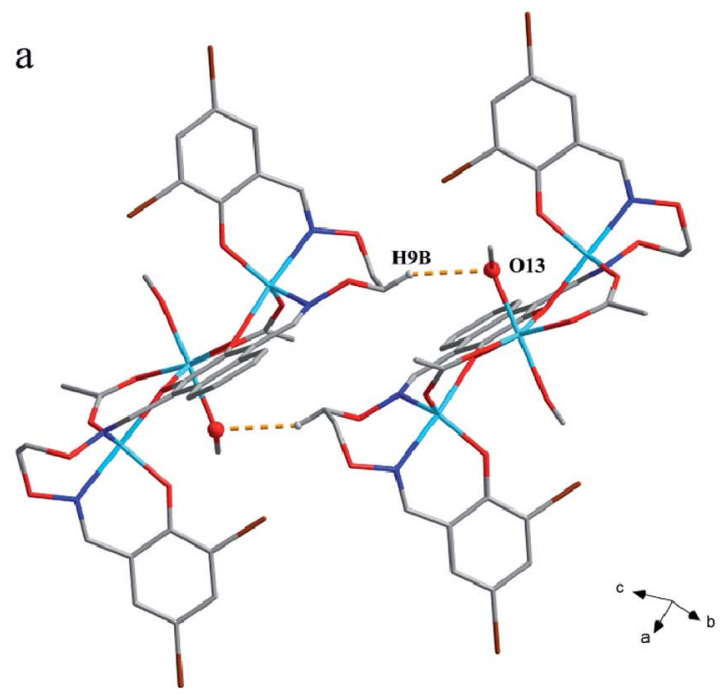

b
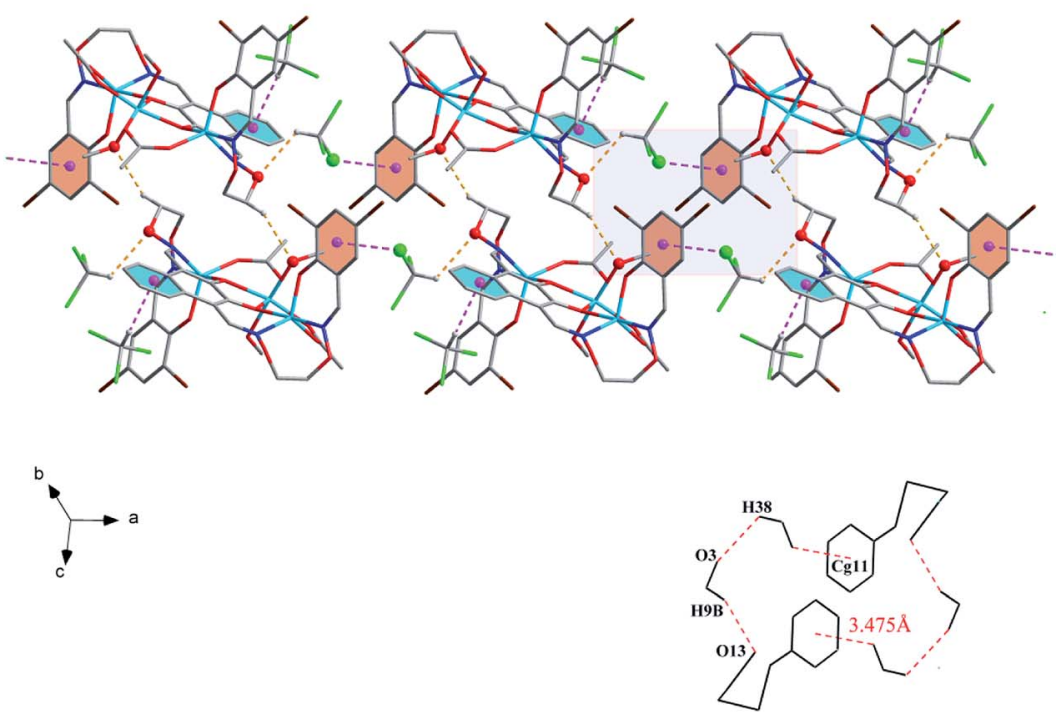

Fig. 6 (a) View of the dimer structure by intermolecular $\mathrm{C}-\mathrm{H} \cdots \mathrm{O}$ interactions. (b) View of the $1 \mathrm{D}$ supramolecular chain by intermolecular $\mathrm{C}-\mathrm{H} \cdots \mathrm{O}$ and $\mathrm{C}-\mathrm{Cl} \cdots \pi$ interactions. 


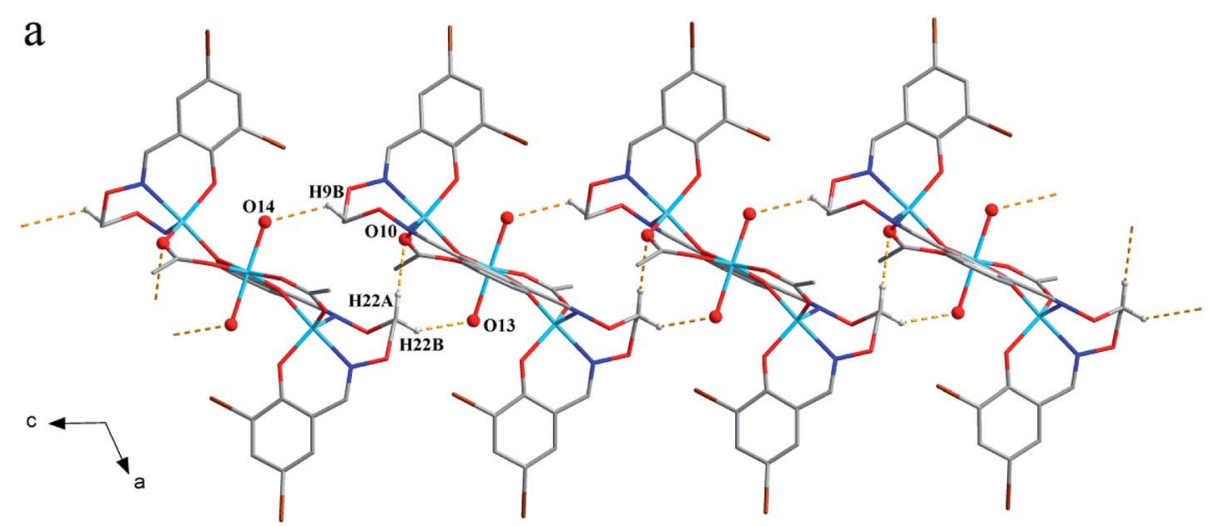

\section{$b$}

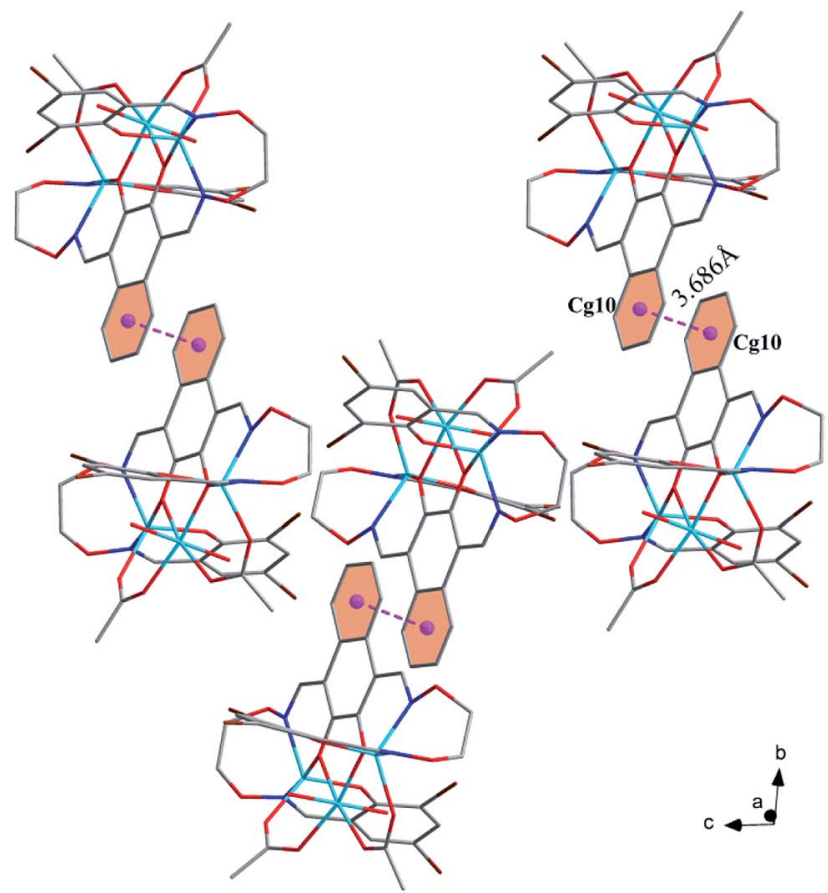

Fig. 7 (a) View of the 1D structure by intermolecular $\mathrm{C}-\mathrm{H} \cdots \mathrm{O}$ interactions. (b) View of the 2D supramolecular layered by intermolecular $\pi \cdots \pi$ interactions.

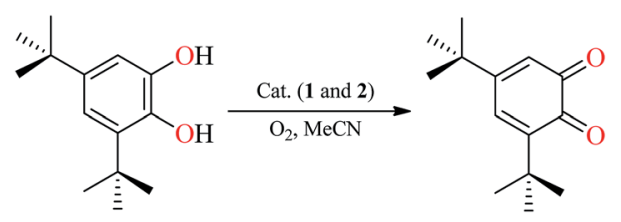

Scheme 2 Catalytic oxidation of 3,5-DTBC to 3,5-DTBQ in MeCN solvent.

makes it easy to be oxidized into 3,5-di-tert-butylquinone (3,5DTBQ) ${ }^{29}$ Before embarking on detailed kinetic study, we first investigated the ability of the complexes in acetonitrile solvent to mimic the active site of catechol oxidase by treating $2.5 \times$ $10^{-5} \mathrm{M}$ solutions of the complexes with $2.5 \times 10^{-3} \mathrm{M}(100$ equivalents) of 3,5-DTBC under aerobic condition (Scheme 2).
With $\mathbf{1}$, for instance, the time-dependent UV-vis spectra scan was recorded in pure acetonitrile solution under aerobic condition at room temperature. The course of the reaction was recorded per 5 min (Fig. 8). Spectra bands of 1 appears at 375 and $411 \mathrm{~nm}$, whereas 3,5-DTBC showed single band at $278 \mathrm{~nm}$. It is generally known that 3,5-DTBQ shows maximum absorption in UV-vis spectrum at $400 \mathrm{~nm}$ in pure acetonitrile solution. After the addition of 3,5-DTBC, the time dependent spectra scan showed very smooth growing of quinone band and finally a peak at $400 \mathrm{~nm}$ is formed after $24 \mathrm{~h}$ which is very close to the value reported by Krebs $e t ~ a l .{ }^{30}$ and the spectra bands of $\mathbf{1}$ was hidden by the new absorption, which indicated the formation of the quinine derivative, 3,5-DTBQ. The difference in absorbance $(\Delta A)$ at $400 \mathrm{~nm}$ was plotted against time (min) to obtain the initial rate for that particular catalyst to substrate concentration ratio. A first-order catalytic reaction was observed, with initial 
<smiles>Cc1cc(/C=N/CCN2CCNCC2)c(O)c(/C=N/CCN2CCNCC2)c1</smiles>
$\mathrm{HL}^{1}$<smiles></smiles><smiles>Oc1c(Br)cc(Br)cc1/C=N/OCCO/N=C/c1c(O)c(O)c2ccccc2c1/C=N/OCCO/N=C/c1cc(Br)cc(Br)c1O</smiles>

Scheme 3 Structures of the ligands mentioned in Table 5.

rate of $3.81 \times 10^{-3} \mathrm{~min}^{-1}$. The product was purified and identified by ${ }^{1} \mathrm{H}$ NMR spectroscopy.

To investigated the autooxidation ability of the substrate, control experiments without Co catalysts were also performed. Solution of 3,5-DTBC $\left(2.5 \times 10^{-3} \mathrm{M}\right)$ was prepared in MeCN and the time-dependent UV-vis spectra scan was also recorded per 5 min under the same condition. As shown in Fig. S1, $\dagger$ there was almost no changes observed in UV-vis spectra up to 60 minutes,

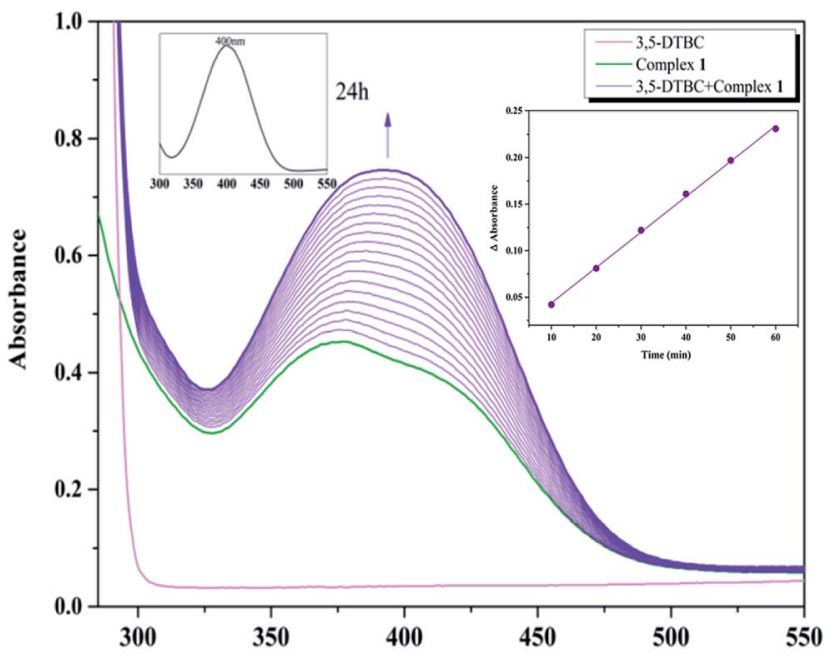

Fig. 8 Changes observed in UV-vis spectra of 1 in MeCN up to 90 minutes (conc. $2.5 \times 10^{-5} \mathrm{M}$ ) upon addition of 100 -fold 3,5-DTBC $\left(2.5 \times 10^{-3} \mathrm{M}\right)$. The inset shows the absorption after $24 \mathrm{~h}$, and plot of the difference in absorbance $(\Delta A)$ versus time to evaluate the initial rate of the catalytic oxidation of 3,5-DTBC by 1 in $\mathrm{MeCN}$.

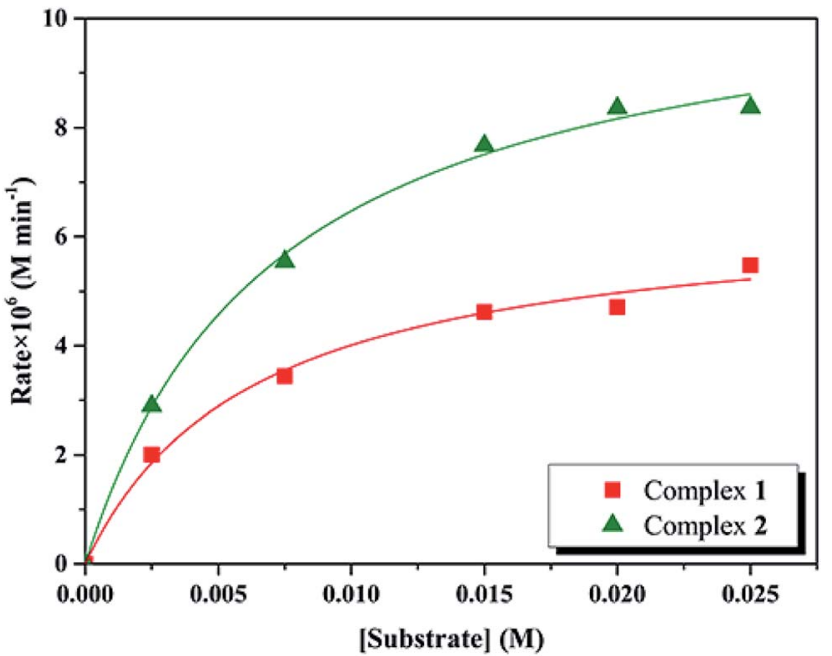

Fig. 9 Plot of initial rates versus substrate concentration for the oxidation reaction catalyzed by 1 and 2 in $\mathrm{MeCN}$.

which proved that our complexes as catalyst could really improve the oxidation efficiency.

\section{Kinetics study}

Kinetic studies of the catecholase activities of the catalysts were determined by treating $2.5 \times 10^{-5} \mathrm{M}$ solutions of the complexes and monitoring the increase of the concentration of 3,5-DTBC, ranging from $2.5 \times 10^{-3}$ to $2.5 \times 10^{-2} \mathrm{M}$. The rate constants for the catalyst complexes were determined from that plot by initial rate method. Assuming rate $\left(\mathrm{M} \mathrm{min}^{-1}\right)$ is the initial rate, plot of rate versus substrate concentration ([substrate]) for the oxidation reaction catalyzed by 1 and 2 is drawn in Fig. 9. It is found that rate followed saturation kinetics with respect to [substrate]. At sufficiently low [substrate], plot of rate versus [substrate] is linear. When [substrate] becomes sufficiently high, the catalyst (here is model complexes) is saturated, the rate of reaction is zero-order and tends toward a limiting value, maximum velocity $\left(V_{\max }\right)$. Both complexes show saturation kinetics and

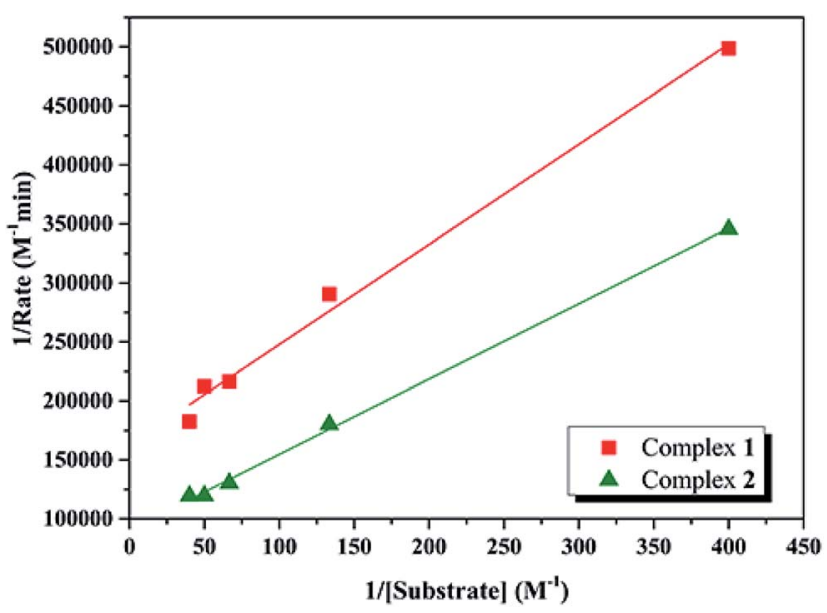

Fig. 10 Lineweaver-Burk oxidation reaction plot for 1 and 2 in $\mathrm{MeCN}$. 
Table 4 Kinetic parameters for the oxidation of 3,5-DTBC catalyzed by 1 and 2

\begin{tabular}{llll}
\hline Complex & $V_{\max }\left(\mathrm{M} \mathrm{min}^{-1}\right)$ & $K_{\mathrm{M}}(\mathrm{M})$ & $K_{\text {cat }}\left(\mathrm{h}^{-1}\right)$ \\
\hline $\mathbf{1}$ & $6.14 \times 10^{-6}$ & $5.20 \times 10^{-3}$ & 14.7 \\
2 & $1.10 \times 10^{-5}$ & $7.09 \times 10^{-3}$ & 26.4 \\
\hline
\end{tabular}

a treatment based on the Michaelis-Menten model seems to be appropriate.

In order to calculate the values of binding constant $\left(K_{\mathrm{M}}\right)$, maximum velocity $\left(V_{\max }\right)$, and rate constant (i.e., turn over number, $K_{\text {cat }}$ ) for the complexes, the Lineweaver-Burk graph of 1 /rate against $1 /[$ substrate] is plotted (Fig. 10). Corresponding plots is linear and parameters are calculated from the following equation, $1 /$ rate $=\left\{K_{\mathrm{M}} / V_{\max }\right\} \times\{1 /[$ substrate $]\}+1 / V_{\text {max }}$, and $K_{\text {cat }}$ are evaluated by applying the equation $K_{\text {cat }}=\left(V_{\max } /[\right.$ cat.]). Some of the kinetic parameters are tabulated in Table 4 . The values of $K_{\text {cat }}$ are $14.72 \mathrm{~h}^{-1}$ and $26.39 \mathrm{~h}^{-1}$ for 1 and 2 , respectively. Thus, solvent effect could be responsible for the differences observed in the catecholase activities. Among the cobalt complexes produced as mimics for catechol oxidase, the number of $\mathrm{Co}$ (II) complexes studied as models for catechol oxidase is relatively low. The $K_{\text {cat }}$ values of complexes 1 and 2 and other reported Co(II) complexes are shown in Table 5. The exciting thing is that Salamo-type complexes as the catechol oxidase model complexes in our work exhibit good properties compared with other types of complexes reported.

The catecholase model complexes have been reported to relate to several factors such as metal-metal distance, lability of exogenous ligands, coordination configuration and electrochemical properties. ${ }^{31}$ A probable explanation for the catecholase catalytic reactivity of two complexes were mainly related to its coordination environment. The five-coordinated cobalt(II) atom has an unsaturated vacancy, and it could combine with the catechol substrates. Meanwhile, the presence of acetate which may be displaced by the catechol substrate has been shown to be important. An acetate ligand would

Table $5 K_{\text {cat }}$ values of complexes 1, 2 and other reported Co(॥) complexes

\begin{tabular}{llcl}
\hline Complex $^{a}$ & Solvent & $K_{\text {cat }}\left(\mathrm{h}^{-1}\right)$ & Ref. \\
\hline$\left[\mathrm{Co}_{2}\left(\mathrm{~L}^{2}\right)\left(\mathrm{H}_{2} \mathrm{O}\right)_{2}(\mathrm{OAc})_{2}\right]^{+b}$ & MeOH & 45.9 & 32 \\
{$\left[\mathrm{Co}_{2}\left(\mathrm{~L}^{3}\right)\left(\mathrm{H}_{2} \mathrm{O}\right)_{2}(\mathrm{OAc})_{2}\right]^{+b}$} & MeOH & 42.9 & 32 \\
{$\left[\mathrm{Co}_{2}\left(\mathrm{~L}^{1} \mathrm{H}\right)\left(\mathrm{H}_{2} \mathrm{O}\right)_{2}(\mathrm{OAc})_{2}\right]^{2+b}$} & MeOH & 447 & 32 \\
{$\left[\mathrm{Co}_{2}(\mathrm{EGTB}) \mathrm{Cl}_{2}\right]^{2+c}$} & MeOH-Tris-HCl & 7.02 & 33 \\
& buffer, pH 8.0 & & \\
& MeOH-Tris-HCl & 1.14 & 33 \\
& buffer, pH 7.6 & & \\
& MeOH-Tris-HCl & 0.9 & 33 \\
& buffer, pH 7.3 & & \\
$\mathbf{1}^{b}$ & MeCN & 14.72 & This work \\
$\mathbf{2}^{b}$ & MeCN & 26.39 & This work
\end{tabular}

${ }^{a}$ Structures of ligands are shown in Scheme $3 .{ }^{b}$ Substrate: 3,5 -di-tertbutylcatechol. ${ }^{c}$ Substrate: catechol. contribute a negatively charged moiety capable of facilitating the catalytic process.

\section{Conclusions}

As a result of the introduction of different solvent molecules, two new homotrinuclear Co(II) complexes $\mathbf{1}$ and 2 with a bis (Salamo)-type tetraoxime ligand $\mathrm{H}_{4} \mathrm{~L}$, were designed and synthesized. Methanol as coordinating solvent generates the coordination of methanol molecules. In the presence of i-PrOH/ $\mathrm{H}_{2} \mathrm{O}$, water molecules coordinate to the central $\mathrm{Co}$ (II) rather than isopropanol. 1 and $\mathbf{2}$ differ only by the solvent molecules coordinated to central $\mathrm{Co}$ (II) ions. Two terminal $\mathrm{Co}$ (II) ions, located at the $\mathrm{N}_{2} \mathrm{O}_{2}$ coordination spheres of Salamo moieties, are both in a distorted trigonal-bipyramidal geometries, whereas the one in the central $\mathrm{O}_{4}$ cavity shows an octahedral geometry with the two solvent molecules. As far as we know, the present work is the first to report the catecholase activities of Salamo-type complexes. The catalytic reaction follows Michaelis-Menten enzymatic reaction kinetics with turnover number 14.72 $\mathrm{h}^{-1}$ and $26.39 \mathrm{~h}^{-1}$ for 1 and 2 , respectively.

\section{Acknowledgements}

This work was supported by the National Natural Science Foundation of China (21361015), which is gratefully acknowledged.

\section{References}

1 (a) Y. X. Sun, S. T. Zhang, Z. L. Ren, X. Y. Dong and L. Wang, Synth. React. Inorg., Met.-Org., Nano-Met. Chem., 2013, 43, 995-1000; (b) H. L. Wu, G. L. Pan, Y. C. Bai, H. Wang, J. Kong, F. R. Shi, Y. H. Zhang and X. L. Wang, J. Chem. Res., 2014, 38, 211-217; (c) H. L. Wu, G. L. Pan, Y. C. Bai, H. Wang, J. Kong, F. R. Shi, Y. H. Zhang and X. L. Wang, Res. Chem. Intermed., 2015, 41, 3375-3388; (d) H. L. Wu, G. L. Pan, Y. C. Bai, H. Wang, J. Kong, F. R. Shi, Y. H. Zhang and X. L. Wang, J. Coord. Chem., 2013, 66, 2634-2646; (e) W. K. Dong, J. C. Ma, L. C. Zhu and Y. Zhang, New J. Chem., 2016, 40, 6998-7010.

2 (a) P. Wang and L. Zhao, Spectrochim. Acta, Part A, 2015, 135, 342-350; (b) P. Wang and L. Zhao, Synth. React. Inorg., Met.Org., Nano-Met. Chem., 2016, 46, 1095-1101; (c) H. L. Wu, Y. C. Bai, Y. H. Zhang, G. L. Pan, J. Kong, F. R. Shi and X. L. Wang, Z. Anorg. Allg. Chem., 2014, 640, 2062-2071; (d) H. L. Wu, C. P. Wang, F. Wang, H. P. Peng, H. Zhang and Y. C. Bai, J. Chin. Chem. Soc., 2015, 62, 1028-1034; (e) L. Xu, L. C. Zhu, J. C. Ma, Y. Zhang, J. Zhang and W. K. Dong, Z. Anorg. Allg. Chem., 2015, 641, 2520-2524; (f) L. Q. Chai, K. Y. Zhang, L. J. Tang, J. Y. Zhang and H. S. Zhang, Polyhedron, 2017, 130, 100-107; $(g)$ L. Q. Chai, L. J. Tang, L. C. Chen and J. J. Huang, Polyhedron, 2017, 122, 228-240; (h) W. K. Dong, P. F. Lan, W. M. Zhou and Y. Zhang, J. Coord. Chem., 2016, 7, 1-22; (i) P. P. Liu, C. Y. Wang, M. Zhang and X. Q. Song, Polyhedron, 2017, 129, 133-140. 
3 (a) L. Wang, J. C. Ma, W. K. Dong, L. C. Zhu and Y. Zhang, Z. Anorg. Allg. Chem., 2016, 642, 834-839; (b) J. C. Ma, X. Y. Dong, W. K. Dong, Y. Zhang, L. C. Zhu and J. T. Zhang, J. Coord. Chem., 2016, 69, 149-159; (c) X. Y. Dong, S. F. Akogun, W. M. Zhou and W. K. Dong, J. Chin. Chem. Soc., 2017, 64, 412-419; (d) C. H. Tao, J. C. Ma, L. C. Zhu, Y. Zhang and W. K. Dong, Polyhedron, 2017, 128, 38-45; (e) Y. J. Dong, X. Y. Dong, W. K. Dong, Y. Zhang and L. S. Zhang, Polyhedron, 2017, 123, 305-315; (f) Y. J. Dong, J. C. Ma, L. C. Zhu, W. K. Dong and Y. Zhang, J. Coord. Chem., 2017, 70, 103-115; (g) X. Q. Song, G. Q. Cheng and Y. A. Liu, Inorg. Chim. Acta, 2016, 450, 386-394; (h) X. Q. Song, P. P. Liu, Y. A. Liu, J. J. Zhou and X. L. Wang, Dalton Trans., 2016, 45, 8154-8163; (i) X. Q. Song, Y. Q. Peng, G. Q. Cheng, X. R. Wang, P. P. Liu and W. Y. Xu, Inorg. Chim. Acta, 2015, 427, 13-21.

4 (a) C. Y. Chen, J. W. Zhang, Y. H. Zhang, Z. H. Yang, H. L. Wu, G. L. Pan and Y. C. Bai, J. Coord. Chem., 2015, 68, 1054-1071; (b) H. L. Wu, Y. C. Bai, Y. H. Zhang, Z. Li, M. C. Wu, C. Y. Chen and J. W. Zhang, J. Coord. Chem., 2014, 67, 3054-3066; (c) H. L. Wu, H. Wang, X. L. Wang, G. L. Pan, F. R. Shi, Y. H. Zhang, Y. C. Bai and J. Kong, New J. Chem., 2014, 38, 1052-1061; (d) H. L. Wu, G. L. Pan, Y. C. Bai, Y. H. Zhang, H. Wang, F. R. Shi, X. L. Wang and J. Kong, J. Photochem. Photobiol., B, 2014, 135, 33-43.

5 L. H. Li, W. K. Dong, Y. Zhang, S. F. Akogun and L. Xu, Appl. Organomet. Chem., DOI: 10.1002/aoc.3818.

6 (a) P. P. Liu, L. Sheng, X. Q. Song, W. Y. Xu and Y. A. Liu, Inorg. Chim. Acta, 2015, 434, 252-257; (b) X. Q. Song, P. P. Liu, Z. R. Xiao, X. Li and Y. A. Liu, Inorg. Chim. Acta, 2015, 438, 232-244; (c) Y. A. Liu, C. Y. Wang, M. Zhang and X. Q. Song, Polyhedron, 2017, 127, 278-286.

7 (a) W. K. Dong, J. C. Ma, L. C. Zhu, Y. Zhang and X. L. Li, Inorg. Chim. Acta, 2016, 445, 140-148; (b) W. K. Dong, P. F. Lan, W. M. Zhou and Y. Zhang, J. Coord. Chem., 2016, 65, 1272-1283.

8 (a) B. J. Wang, W. K. Dong, Y. Zhang and S. F. Akogun, Sens. Actuators, B, 2017, 247, 254-264; (b) Y. J. Dong, X. L. Li, Y. Zhang and W. K. Dong, Supramol. Chem., 2017, 29, 518527.

9 (a) W. K. Dong, J. C. Ma, L. C. Zhu, Y. X. Sun, S. F. Akogun and Y. Zhang, Cryst. Growth Des., 2016, 16, 6903-6914; (b) X. Y. Dong, Y. X. Sun, L. Wang and L. Li, J. Chem. Res., 2012, 36, 387-390; (c) X. Y. Dong, Q. P. Kang, B. X. Jin and W. K. Dong, Z. Naturforsch., 2017, 72, 415-420; (d) S. Akine, T. Taniguchi and T. Nabeshima, Chem. Lett., 2001, 30, 682683.

10 S. Akine, T. Taniguchi and T. Nabeshima, Inorg. Chem., 2008, 47, 3255-3264.

11 (a) Y. X. Sun and X. H. Gao, Synth. React. Inorg., Met.-Org., Nano-Met. Chem., 2011, 41, 973-978; (b) Y. X. Sun, L. Xu, T. H. Zhao, S. H. Liu, G. H. Liu and X. T. Dong, Synth. React. Inorg., Met.-Org., Nano-Met. Chem., 2013, 43, 509513; (c) L. Q. Chai, G. Wang, Y. X. Sun, W. K. Dong, L. Zhao and X. H. Gao, J. Coord. Chem., 2012, 65, 1621-1631.

12 (a) Z. F. Li, S. J. Wu, H. Ding, H. Lu, J. Y. Liu, Q. S. Huo, J. Q. Guan and Q. B. Kan, New J. Chem., 2013, 37, 4220-
4229; (b) P. Yu, A. L. Li, H. Liang and J. Lu, J. Polym. Sci., 2007, 45, 3739-3746.

13 C. Gerdemann, C. Eicken and B. Krebs, Acc. Chem. Res., 2002, 35, 183-191.

14 A. Banerjee, S. Sarkar, D. Chopra, E. Colacio and K. K. Rajak, Inorg. Chem., 2008, 47, 4023-4031.

15 J. Anekwe, A. Hammerschmidt, A. Rompel and B. Krebs, $Z$. Anorg. Allg. Chem., 2006, 632, 1057-1066.

16 P. Chakraborty, J. Adhikary, B. Ghosh, R. Sanyal, S. K. Chattopadhyay, A. Bauzá, A. Frontera, E. Zangrando and D. Das, Inorg. Chem., 2014, 53, 8257-8269.

17 S. Torelli, C. Belle, I. Gautier-Luneau, J. L. Pierre, E. SaintAman, J. M. Latour, L. Le Pape and D. Luneau, Inorg. Chem., 2000, 39, 3526-3536.

18 (a) M. J. Gajewska, W. M. Ching, Y. S. Wen and C. H. Hung, Dalton Trans., 2014, 43, 14726-14736; (b) P. Kar, Y. Ida, T. Kanetomo, M. G. Drew, T. Ishida and A. Ghosh, Dalton Trans., 2015, 44, 9795-9804.

19 S. Akine, T. Taniguchi, W. K. Dong, S. Masubuchi and T. Nabeshima, J. Org. Chem., 2005, 70, 1704-1711.

20 H. A. Tran, J. Collins and P. E. Georghiou, New J. Chem., 2008, 32, 1175-1182.

21 G. M. Sheldrick, SHELXS 97, Program for crystal structure solution, University of Göttingen, Göttingen, Germany, 1997.

22 G. M. Sheldrick, SHELXL 97, Program for crystal structure refinement, University of Göttingen, Göttingen, Germany, 1997.

23 M. Tümer, H. Köksal, M. K. Sener and S. Serin, Transition Met. Chem., 1999, 24, 414-420.

24 Y. Yang, P. F. Yan, P. Gao, T. Gao, G. F. Hou and G. M. Li, J. Inorg. Organomet. Polym., 2013, 23, 1211-1218.

25 W. K. Dong, Y. X. Sun, C. Y. Zhao, X. Y. Dong and L. Xu, Polyhedron, 2010, 29, 2087-2097.

26 T. Konno, K. Tokuda, J. Sakurai and K. I. Okamoto, Bull. Chem. Soc. Jpn., 2000, 73, 2767-2773.

27 (a) Y. X. Sun, C. Y. Li, C. J. Yang, Y. Y. Zhao, J. Q. Guo and B. Yu, Chin. J. Inorg. Chem., 2016, 32, 327-335; (b) Y. X. Sun, L. Wang, X. Y. Dong, Z. L. Ren and W. S. Meng, Synth. React. Inorg., Met.-Org., Nano-Met. Chem., 2013, 43, 599-603; (c) Y. X. Sun, R. E. Lu, X. R. Li, Y. Y. Zhao and C. Y. Li, Chin. J. Inorg. Chem., 2015, 31, 1055-1062; (d) L. Q. Chai, Y. X. Li, L. C. Chen, J. Y. Zhang and J. J. Huang, Inorg. Chim. Acta, 2016, 444, 193-201; (e) L. Zhao, X. T. Dang, Q. Chen, J. X. Zhao and L. Wang, Synth. React. Inorg., Met.-Org., Nano-Met. Chem., 2013, 43, 1241-1246; (f) L. Zhao, L. Wang, Y. X. Sun, W. K. Dong, X. L. Tang and X. H. Gao, Synth. React. Inorg., Met.-Org., Nano-Met. Chem., 2012, 42, 1303-1308.

28 (a) X. Q. Song, G. Q. Cheng, X. R. Wang, W. Y. Xu and P. P. Liu, Inorg. Chim. Acta, 2015, 425, 145-153; (b) Y. X. Sun, Y. Y. Zhao, C. Y. Li, B. Yu, J. Q. Guo and J. Li, Chin. J. Inorg. Chem., 2016, 32, 913-920; (c) L. Q. Chai, K. H. Mao, J. Y. Zhang, K. Y. Zhang and H. S. Zhang, Inorg. Chim. Acta, 2017, 457, 34-40; (d) L. Q. Chai, J. J. Huang, J. Y. Zhang and Y. X. Li, J. Coord. Chem., 2015, 68, 1224-1237. 29 P. Seth, L. K. Das, M. G. B. Drew and A. Ghosh, Eur. J. Inorg. Chem., 2012, 13, 2232-2242. 
30 F. Zippel, F. Ahlers, R. Werner, W. Haase, H. F. Nolting and B. Krebs, Inorg. Chem., 1996, 35, 3409-3419.

31 (a) S. J. Smith, C. J. Noble, R. C. Palmer, G. R. Hanson, G. Schenk, L. R. Gahan and M. J. Riley, J. Biol. Inorg. Chem., 2008, 13, 499-510; (b) S. Y. Shaban, R. Aelm, M. M. Ibrahim, M. A. Mohamed and E. R. Van, Dalton Trans., 2015, 44, 14110-14121; (c) S. Y. Shaban,
A. M. Ramadan and E. R. Van, J. Coord. Chem., 2012, 65, 2415-2431.

32 A. Banerjee, A. Guha, J. Adhikary, A. Khan, K. Manna, S. Dey, E. Zangrando and D. Das, Polyhedron, 2013, 60, 102-109.

33 J. H. Qiu, Z. R. Liao, X. G. Meng, L. Zhu, Z. M. Wang and K. B. Yu, Polyhedron, 2005, 24, 1617-1623. 